\title{
Comparative Gross Anatomical Studies on Oropharynx of Flamingo, Great Indian Horned Owl, Budgerigar, Peahen and Emu
}

\author{
K. Rajalakshmi*, P. Sridevi and M. Siva Kumar \\ Department of Veterinary Anatomy and Histology, Rajiv Gandhi Institute of Veterinary \\ Education and Research, Kurumbapet, Puducherry-605010, India \\ *Corresponding author
}

Keywords

Oropharynx,

Roof, Floor,

Choanal cleft

Article Info

Accepted:

12 February 2020

Available Online:

10 March 2020

\section{A B S T R A C T}

The roof of the oropharynx was formed by the hard palate and its anterior two third was divided by a median palatine ridge into right and left halves in flamingo followed by great Indian horned owl, emu, peahen. In buderiger the median palatine ridge was not noticed. The hard palate presented a long single median cleft called the choanal cleft which connected the oral cavity to the nasal cavity. The shape of the avian choanal cleft presented species to species difference in the present study. The floor of the oral cavity varied in different avian species, the floor of the oropharynx consists of mandible, tongue and laryngeal mound. The tongue of emu was greatly reduced in comparison to the bill length. The tongue of all species showed the presence of a papillary crest which were separated the body from the root of the tongue.

\section{Introduction}

The oral cavity of the birds had a wide variation and due to its adaptation to different feeding habits, and climate conditions which are reflected on their shape and structures of their bills and tongue. Beak or bill adapted to carry out a multitude of functions, including preening, manipulating objects, fighting, counter ship, feeding young and most importantly, the acquisition and handling of food. According to beak plays an important part in prehension and in the physical preparation of food and in some species such as parrots it is even used as an aid to locomotion. The morphological characters of the tongue and its adaptation to lifestyle, feeding habits and habitats, and surrounding environmental conditions, due to the important role of the tongue in capturing, filtering, and manipulating food. The anatomy of the oropharynx and tongue is important to 
identify structural features that may influence nutrition, food intake and ingestion, as well as to provide a foundation for recognition of pathology in this region. Therefore, the purpose of this study is thus to examine of six avian species in order to compare results with those from previous reports on other birds.

\section{Materials and Methods}

The species used in these comparative studies were peahen, flamingo, great Indian horned owl, budgerigar and emu brought for post mortem examination to the Department of Veterinary Pathology Rajiv Gandhi Institute of Veterinary Education and Research, Puducherry. The beak along with tongue was collected and rinsed in saline and immersed in $10 \%$ neutral buffered formalin, various gross morphological were recorded by using a digital camera with $12 \mathrm{X}$ zoom (Nikon).

\section{Results and Discussion}

The oral and pharyngeal cavity was not having clear line of demarcation due to lack of soft palate and so forming a common oropharyngeal cavity in all birds in the present study. The oropharyngeal cavity consisted of roof formed by incomplete hard palate and floor formed by mandible, tongue and laryngeal mound in all the birds. Abumandour (2014) in Eurasian Hobby stated that the lips and teeth was absent and their function was replaced by the edges of the beak and gizzard.

\section{Beak}

The beak consists of upper and lower beak with thin keratinized layer of epidermis. McLelland (1990) in adult chicken stated that the upper jaw of the medial border had culmen and the lower is the gonys. The upper beak is formed by premaxilla and the lower was formed by mandible. The shape of the beak varies in the present study. The upper beak is curved, convex and the lower beak was concave in flamingo followed by great Indian horned by peahen, emu and budgerigar. In the budgerigar upper beak varies is stout and sharp tipped and strongly curved with pointed tip and closes over with a small blunt lower beak where as in peahen the upper and lower beak was almost equal in size, with short thick triangular beak while in emu beak was very broad with triangular shaped .Nickel et al., (1977) reported that the upper beak completely covered the lower beak when mouth was closed as reported in fowl and pigeon. In owl upper beak had a sharp short curved downward facing hooked at the end and lower beak was blunt and conical while in flamingo The upper and lower bill was large, long and angled downward. The upper bill was thin and flat strongly concave, and the lower bill was strongly convex and was a trough with ridges in bill. The shape of the beak varies in different species, broad and shovel shaped in Igwebuike and Anagor (2013) in Muscovy duck, Rossi et al., (2005) stated that curved, flat, hard with a sharp extremity in partridge, Nickel et al., (1977) stated that spoon-shaped in duck and goose. Abumandour (2014) in Eurasian Hobby sharp, thin and pointed rostrally. In flamingo tomina with thick serrations were noticed whereas in great Indian horned, peahen, emu, budgerigar tomina was smooth edged and sharp.

\section{Roof of the oropharynx}

The roof of palate the oropharynx was formed by the hard palate and was divided into two parts namely anterior and posterior parts. In emu the roof was composed of pigmented and non-pigmented parts. The anterior two third of the roof of the hard palate was pigmented while in the other species in the present study, the hard palate was non pigmented Similar observations reported by Crole and Soley 
(2010) in emu. The roof of the oropharynx (Fig. 1). was formed by the hard palate and its anterior two third was divided by a median palatine ridge into right and left halves in flamingo followed by great Indian horned owl, emu, peahen. In buderiger the median palatine ridge was not noticed. In flamingo the median palatine ridge was more prominent and extended upto the choanal cleft. In great Indian horned owl the median palatine ridge was present in anterior one third of the hard palate. While in emu the ridge was prominent in two third of the hard palate while it was faint in posterior one third. In peahen the rostral one third of the hard palate had median palatine ridge. Jayachitra $e t$ al., 2015 in guinea fowl reported that a median palatine ridge in the anterior two third of the hard palate. Igwebuike 2013 in Muscovy duck had ridge on its rostral two third of the hard palate. In great Indian horned owl, peahen the median palatine ridge presented rostrally a median palatine swelling, Jayachitra et al., 2015 in guinea fowl and Igwebuike and Anagor (2013) in Muscovy duck while in buderiger rostral to the plate a fleshly vascular cushion. McLelland 1990 in buderiger stated that this vascular cushion along with the tongue aided to hold the food. Abumandour (2014) in Eurasian Hobby reported that a shallow triangular median palatine swelling area rostral to the choanal cleft. In owl the caudal part of the median palatine ridge bearded papillae while other species in the present study did not show papillae. In great Indian horned owl the lateral palatine ridges were present on either side of the medial ridge and extended along two third of the length of the hard palate. The lateral palatine ridges bearded rostral blunt papillae presented a hook like medially directed fold.

In peahen two lateral palatine ridges were observed on either side of median ridges which ran parallel to the median palatine ridge. Then diverged caudo laterally parallel to the beak and cranio caudally directed. The ridge presented along the entire length of the hardpalate. Similar observations were noticed by Gupt et al., (2018) in turkey and Jayachitra et al., (2015) in guinea fowl. In the great Indian horned owl a transverse fold studded with a row of blunt papillae was observed in the rostral one fourth of the hard palate which connected the transverses fold connected the lateral and medial palatine ridges. In peahen, behind the median palatine ridge four transverse rows of caudally directed papillae were observed on either side of the choanal cleft. A single transverse row of large backward directed pharyngeal papillae was observed at the junction between choanal cleft and infundibular cleft which marked the end of the oral cavity. Jayachitra et al., (2015) in guinea fowl had observed six transverse rows of papillae. However Nickel et al., (1977) reported that in domestic birds several row of transverse rows of papillae. Gupt et al., 2018 in turkey recorded three to four transverse rows of papillae. Igwebuike and Anagor (2013) in Muscovy duck observed a complete absence of papillae on the hard palate. Nickel et al., 1977 reported that in duck reported that these papillae were restricted only to the apical region. These papillae encircling the choanal cleft and those on the hard palate could have a mechanical function their by obstructing the escape of food into the choanal cleft and thus could aid in movement of food into oesophagus. The hard palate presented a long single median cleft called the choanal cleft which connected the oral cavity to the nasal cavity. The shape of the avian choanal cleft presented species to species difference in the present study. In emu, flamingo, peahen and owl, the choanal cleft was present in the posterior one third. In emu the choanae was triangular shape in hard palate and was flanked by a two small folds laterally with two internal nares separated by a median grooved septum similar 
observations was reported by Crole and Soley 2010 in emu in ostrich the choanae was very short and was present on the posterior part of the hard palate and it formed an inverted $\mathrm{V}$ shaped depression.

In the great Indian horned owl the chonal cleft was into a rostral narrow part and a caudal wide part which had the shape of pentagon and showed the openings of the posterior nares separated by a median shallow fold. Whereas Abumandour in Eurasian Hobby stated that a rostral narrow part and a wider caudal part. In budgerigar the single median choanal slit was rostrally narrow and wide caudally. The choanal slit in its middle presented the single opening of two combined eustachian tubes. This is in accordance to the findings in budgerigar by McLelland 1990. In flamingo the choanal slit presented a rostrally narrow and a caudal wide part. In peahen choanal cleft is narrow rostrally and broad caudally. Similar observations reported by Gupta et al., 2018 in turkey. While Nickel et $a l ., 1977$ reported that in pigeon the palatine cleft was very long but short in duck and goose.

Caterina et al., 2011 observed bell shaped choanal cleft in ostrich. In all the species of the present study the free margins of the choanal slit presented caudomedially directed serrated papillae except in emu. All though in owl these papillae were more prominent. More over the area surrounded the choanal cleft was also studded with papillae in all species. In budgerigar, great horned owl, flamingo the region surrounding the post part of the choanal cleft was studded with numerous rows of caudally directed papillae. The pharyngeal roof was occupied by the infundibular slit which was a median longitudinal fissure representing a common opening of the two auditory tubes. The choanae and infundibular slit opens together in budgerigar.

\section{Floor of the oropharynx}

The floor of the oral cavity (Fig. 2) varied in different avian species, the floor of the oropharynx consists of mandible, tongue and laryngeal mound. The tongue of emu was greatly reduced in comparison to the bill length. The tongue in present study is divided into three parts as apex, lingual body and root similar observations by Jackowiak and Godynicki (2005) in white tailed eagle. In budgerigar the apex of the tongue was broad sieve like and had numerous longitudinal lines whereas in peahen, flamingo and emu it was pointed. While in great Indian horned owl it was bifid which is agrees with the findings of Abumandour (2014) in Eurasian Hobby. A median sulcus was absent in the tongue of emu while in flamingo presented a well developed median sulcus which is extended to the lingual prominence. In owl the median sulcus was noticed on the apex and body of the tongue. In Golden eagle, white tailed eagle, ducks and geese median groove was prominent Jackowiak and Godynicki (2005), Vollmerhaus and Sinowatz (1992), Komarek 1986 and Parchami (2010). The posterior part of the body of tongue was pigmented in owl whereas in other species it is non pigmented. The body of owl had a studded with numerous papillae which were directed caudally which not observed in other species. While in case of budgerigar the body presented a median ridge continued to the root of the tongue with three to four transverse rows of papillae which were in the form of boiled rice. McLelland (1990) in budgerigar reported that numerous caudally directed papillae. In emu the lateral margin of the tongue showed caudally directed lingual papillae these are in agreement with the studies in emu by Crole and Soley 2010. In peahen lateral margins of the tongue were devoid of papillae. In budgerigar the lateral margins had many backward pointed papillae which aggress with the findings of Bailey et 
al., 1997 in captive bustards. In flamingo fourteen lateral rows of big fang like upward directed papillae were observed throughout on the lateral margins of the lingual body. In great horned Indian owl, the lateral margins of the posterior part of the body have backward directed horny papillae. In flamingo the root of the tongue had a single row of papillae. In emu the root consisted of three or four rudimentary caudal papillae similar observation reported by Jayachitra et al., 2014 in emu. However Catarina et al., 2011 mentioned that lingual papillae were not visualized in ostrich. In peahen root had two to three rows of large and small conical caudally directed papillae. In the present study the tongue of all species showed the presence of a papillary crest which were separated the body from the root of the tongue. A V shaped papillary crest is the common among the avian species of present study. A similar findings was observed in Abumandour (2014) in Eurasian Hobby. However papillary crest was absent in emu

Fig.1 Photograph showing of the roof of the oropharynx -A. Emu B. Flamingo C.Peacock D.Great Indian Horned Owl E. Budgerigar
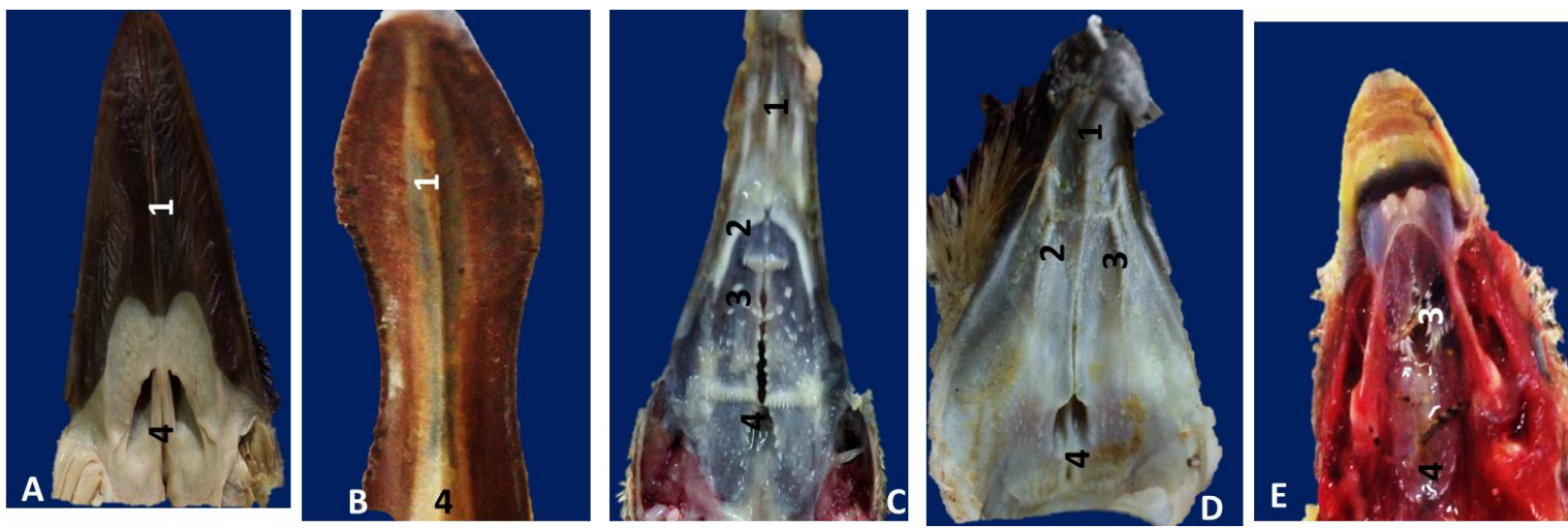

1.Median Palatine Ridge 2.Lateral Palatine 3. Papillae 4. Choanae

Fig 2: Photograph showing of the roof of the oropharynx -A. Emu B. Flamingo C.Peacock D. Great Indian Horned Owl E. Budgerigar

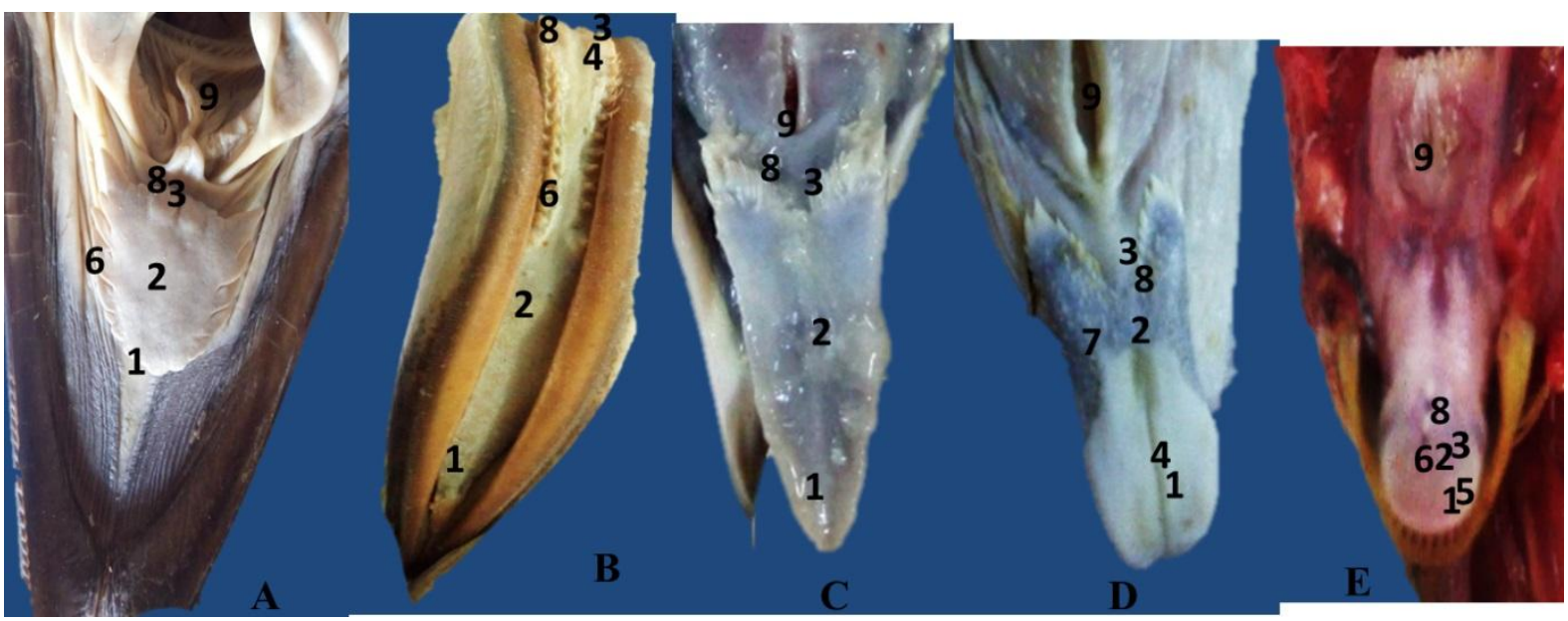

1.Apex 2. Body 3. Root 4. Median Sulcus 5.Longitudinal Lines 6.Lateralpapillae 7. Horny Papillae 8.Papillary Crest 9. Laryngeal mound 


\section{Laryngeal mound}

An elevated structure namely the laryngeal mound (Fig. 2) was situated just caudal to the root of the tongue in all the species of the present study which had the glottis was elongated opening. In peahen the laryngeal mound prominently projected the caudally directed papillae at the root was also observed by Igwebuike and Anagor 2013 in Muscovy duck, in Eurasian Hobby Abumandour (2014), Jayachitra et al., 2015 in guinea fowl, Gupta et al., 2018 in turkey. In flamingo small conical papillae were distributed irregularly on the laryngeal mound and also around the glottis.

McLelland 1990 in adult chicken stated that the caudal part of the mound carried backward pointing papillae which are used in swallowing to grape the food caudally into the oesophagus. In great indian horned owl and budgerigar the laryngeal mound was very prominent and was studded with the blunt papillae. In present study behind the laryngeal mound had a long conical papillae with numerous thin thorny papillae and two large giant papillae on the midline. Abumandour (2014) in Eurasian Hobby and Gupta et al., (2016) in turkey reported similar papillae. A single row of pharyngeal papillae occurred behind the laryngeal mound guinea fowl (Jayachitra et al., 2015).

In flamingo had a 3 to 5 rows of directed papillae. Hassouna, (2002) in duck described 5-7 transverse rows of thin, medium-sized caudally directed papillae. In emu lacked the transverses row of papillae caudal to the infundibular cleft which coincides with a similar observations made by Tadjalli et al., 2008 in ostrich. The caudally directed pointed papillae on the mound might be helpful in the ingestion of solid food particles and pellets and in raking movement of the larynx during swallowing.

\section{Acknowledgement}

Authors are thankful to the Dean Rajiv Gandhi Institute of Veterinary Education and Research, Puducherry for providing the basic infrastructure for carrying out this research work

\section{References}

Abumandour, M.A. (2014). Gross anatomical studies of the oropharyngeal cavity in Eurasian Hobby. J. Life Sci. Res. 1(4): 80-92.

Bailey T. A, Mensah-brown E. P, Samour J. H, Naldo J, Lawrence P, and Garner, G "Comparative morphology of the alimentary tract and its glandular derivatives of captive bustards," J. Anat., vol. 191, pp. 387-398, 1997.

Catarina., Marcio, T. N. R., John, T. S., and Herman, B. G. (2011). Gross anatomical features of the oropharyngeal cavity of the ostrich (Struthio camelus), Pesq. Vet. Bras. Junho. 31: 543-550

Crole, M.R. and Soley, J.T. (2010). Gross morphology of the intra-oral rhamphotheca, oropharynx and proximal esophagus of the emu (Dromaius novaehollandiae). Anat. Histol. Embryol. 39: 207-218

Gupta S.K., Pathak A. and Farooqui M.M. (2016). Anatomy of oropharyngeal cavity of fowl (Gallus domesticus). Ind. J. Vety. Anat. 27 (1): 12-14

Hassouna, E.M.A. (2002). Morphological studies on the pharyngeal cavity of duck (Anas bousius domesticus). Assiut Vet. Med. J. 47: 21-41

Igwebuike, U.M. and Anagor, T.A. (2013): The morphology of the oropharynx and tongue of the Muscovy duck (Cairina moschata).Vet. Arhiv, 83(6): 685-693

Jackowiak H, Godynicki S (2005) Light and scanning electronmicroscopic study of the tongue in the White tailed eagle 
(Haliaeetus albicilla, Accipitridae, Aves). Ann Anat, 187: 251-259

Jayachitra S., Balasundaram K., Iniyah K., Sivagnanam S. and Tamilselvan S. (2015). Morphology of oropharyngeal cavity in guinea fowl (Numida meleagris). Int. J. Advan. Multidisciplinary Res. 2 (4): 99-102

Komarek V, Malinovesky L, Lemez L (1986) Anatomia avium domestica rumet embryologiagalli. Prirodavedavatel' stvoknih a casoposov, Bratyslava.

McLelland, J., 1990: Digestive system. In: A Colour Atlas of Avian Anatomy. Aylesbury, UK: Wolfe Publishing Ltd, pp. 47-49.

Nickel, Schummer, R.A. and Seiferle, E. (1977). Anatomy of the domestic birds. Translation by Siller, W.G. and Wight. P.A.L.Verlag Paul Parey. Berlin: Hamburg

Parchami A, Fatahian Dehkordi RA,
Bahadoran S (2010) Scanning electron microscopy of the tongue in the golden eagle Aquila chrysaetos (Aves) Falconiformes: Accipitridae). World J Zool 5: 257-263.

Roosi, J.R., Baraldi-Artoni, S.M., Olivetra, D., Cruz, C., Franzo, V.S. and Sagula, A. (2005). Morphology of beak and tongue of partridge (Rhynchotus rufescens). Ciencia Rural. 35: 10981102.

Tadjalli, M., Mansouri, S.H. and Poostpasand, A. (2008). Gross anatomy of the oropharyngeal cavity in the ostrich (Struthio camelus). Iranian J. Vet. Res. 9: 316-323

Vollmerhaus B, Sinowatz F (1992) Verdauungsapparat. In: Nickel R, Schummer E, Seiferle E (edn.) Anatomie der Vögel Bd. 5. Lehrbuch der Anatomie der Haustiere, Parey.

\section{How to cite this article:}

Rajalakshmi, K., P. Sridevi and Siva Kumar, M. 2020. Comparative Gross Anatomical Studies on Oropharynx of Flamingo, Great Indian Horned Owl, Budgerigar, Peahen and Emu. Int.J.Curr.Microbiol.App.Sci. 9(03): 1866-1872. doi: https://doi.org/10.20546/ijcmas.2020.903.216 